Jurnal Ilmiah Kesehatan Sandi Husada
https://akper-sandikarsa.e-journal.id/JIKSH
Volume 10| Nomor 2| Desember|2021
e-ISSN: 2654-4563 dan p-ISSN: 2354-6093
DOI 10.35816/jiskh.v10i2.657

Research article

Analisis Faktor Yang Mempengaruhi Kinerja Pegawai Puskesmas

Zulkifli Mansyur ${ }^{1}$, Andi Yusuf ${ }^{2}$, Muhammad Rifai $^{3}$

CrossMark

1,2,3 Kesehatan Masyarakat, Pascasarjana Sekolah Tinggi Ilmu Kesehatan Tamalatea Makassar

\begin{tabular}{|c|c|}
\hline Article Info & Abstrak \\
\hline $\begin{array}{l}\text { Received } \\
\text { 2021-08-01 } \\
\text { Accepted } \\
\text { 2021-10-08 }\end{array}$ & $\begin{array}{l}\text { Pendahuluan; Pelayanan kesehatan bermutu yang diberikan } \\
\text { kepada pasien merupakan tolak ukur bagi keberhasilan } \\
\text { pelayanan, dan berbagai usaha atau kegiatan yang bersifat jasa. } \\
\text { Tujuan; menganalisis faktor yang mempengaruhi kinerja } \\
\text { pegawai puskesmas. Metode; rancangan penelitian yang } \\
\text { digunakan dalam penelitian ini adalah observasional dengan } \\
\text { pendekatan Cross Sectional Study dengan jumlah sampel } \\
\text { sebanyak } 35 \text { pegawai Puskesmas. Hasil; menunjukkan bahwa } \\
\text { variabel pendidikan ( } \rho=0,546) \text {, disiplin kerja }(\rho=0,243) \text {, dan } \\
\text { fasilitas ( } \rho=403) \text { tidak memiliki pengaruh terhadap kinerja } \\
\text { pegawai. Variabel motivasi }(\rho=0,000) \text {, kompensasi ( } \rho=0,000) \text {, } \\
\text { dan lingkungan kerja ( } \rho=0,031) \text { memiliki pengaruh terhadap } \\
\text { kinerja pegawai di Puskemas. Kesimpulan; bahwa motivasi } \\
\text { memiliki kekuatan pengaruh yang paling kuat terhadap kinerja. } \\
\text { Perlunya peningkatan motivasi, kompensasi dan lingkungan } \\
\text { kerja yang baik kepada para pegawai dalam upaya meningkatkan } \\
\text { kinerja pegawai. }\end{array}$ \\
\hline $\begin{array}{l}\text { Kompensasi; } \\
\text { Motivasi Keja; } \\
\text { Kinerja Pegawai; }\end{array}$ & $\begin{array}{l}\text { Introduction; quality health services provided to patients are a } \\
\text { benchmark for the success of services, and various business or } \\
\text { service activities. Objective; analyze the factors that affect the } \\
\text { performance of puskesmas employees. Method; The research } \\
\text { design used in this study was observational with a Cross- } \\
\text { Sectional Study approach with a sample of } 35 \text { Puskesmas } \\
\text { employees. Results; show that the variables of education } \\
\text { ( } \rho=0.546) \text {, work discipline ( } \rho=0.243) \text {, and facilities ( } \rho=403) \text { do } \\
\text { not affect employee performance. Variables of motivation } \\
(\rho=0.000) \text {, compensation ( } \rho=0.000) \text {, and work environment } \\
\text { ( } \rho=0.031) \text { influence the performance of employees at the Public } \\
\text { Health Center. Conclusion; that motivation has the strongest } \\
\text { influence on performance. The need for increased motivation, } \\
\text { compensation, and a good work environment for employees to } \\
\text { improve employee performance. }\end{array}$ \\
\hline
\end{tabular}

Corresponding author

Email

\section{: Zulkifli Mansyur}

: yusuf@stiktamalateamks.ac.id,

\title{
Pendahuluan
}

Kesehatan memiliki peranan besar dalam meningkatkan derajat hidup masyarakat. Karena itu semua negara berupaya menyelenggarakan pelayanan kesehatan yang sebaik-baiknya. Pelayanan kesehatan ini berarti setiap upaya yang diselenggarakan sendiri atau bersama-sama dalam suatu organisasi untuk memelihara dan meningkatkan kesehatan, mencegah dan mengobati penyakit, serta memulihkan kesehatan perorangan, kelompok atau masyarakat (Bukhori, 2015). Pelayanan kesehatan bermutu yang diberikan kepada pasien merupakan tolak ukur bagi keberhasilan pelayanan, dan berbagai usaha atau kegiatan yang bersifat jasa. Secara umum disebutkan bahwa makin efektif suatu pelayanan kesehatan yang diberikan maka semakin tinggi pula mutu pelayanan kesehatan yang diberikan maka semakin tinggi pula mutu pelayanan 
kesehatan tersebut. Puskesmas diharapkan mampu memberikan pelayanan kepada masyarakat secara merata, tidak ada diskriminisasi sehingga pelayanan tersebut menjadi efektif dan efisien (Widianti et al., 2018). Bahwa yang paling dominan dengan pelaksanaan pelayanan kesehatan masyarakat adalah interaksi antara kompetensi dan pelatihan. Kompetensi perawat perlu ditingkatkan dalam rangka optimalisasi pelaksanaan pelayanan kesehatan masyarakat melalui pelatihan, pembinaan melalui tim yang ditugaskan, dan kerjasama dengan rekan sejawat serta memberikan dukungan berupa kebijakan reward dan sanksi seperti jenjang karir perawat (Suprapto Suprapto,etal., 2021).

Sebagai makhluk sosial, pegawai tidak lepas dari berbagai nilai dan norma yang berlaku dalam organisasi. Budaya organisasi dapat mempengaruhi cara-cara pegawai bertingkah laku dan bekerja. Motivasi kerja yaitu sebagai suatu perangsang atau dorongan yang ada pada diri seseorang untuk melakukan sesuatu perbuatan guna mencapau suatu tujuan tertentu. Pengalaman kerja adalah segala sesuatu yang diterima oleh pegawai berupa pengalaman-pengalaman di luar sehingga bisa dikontribusikan kepada mereka dalam mewujudkan tujuan yang berupa penghargaan. Sebuah penelitian tentang pengaruh budaya organisasi, motivasi kerja terhadap kinerja pegawai Giligeng Kabupaten Sumenep menunjukkan bahwa budaya organisasi dan motivasi kerja direspon sangat baik oleh responden sehingga mempunyai pengaruh signifikan terhadap kinerja pegawai, terbukti kebenarannya dan hiptesis diterima (Ismandani et al., 2021). Disiplin kerja merupakan salah satu faktor yang berpengaruh tidak langsung terhadap kinerja pegawai. Penelitian lain tentang pengaruh efikasi diri, disiplin kerja dan pelayanan terhadap kinerja pegawai puskesmas menunjukkan bahwa efikasi diri berpengaruh langsung terhadap kinerja pegawai. Hal ini menunjukkan keyakinan atas kemampuan yang dimiliki oleh pegawai puskesmas dapat memberikan dampak yang positif terhadap kinerja pegawai. Disiplin kerja tidak berpengaruh langsung terhadap kinerja. Disiplin kerja belum mempunyai pengaruh yang positif terhadap kinerja sehingga perlu dilakukan penelitian ulang. Pelayanan berpengaruh lengsung terhadap kinerja, pelayanan yang baik dapat memberikan kontribusi yang baik terhadap kinerja pegawai puskesmas (Susanto, 2018). Bahwa dalam meningkatkan pelayanan kesehatan diperlukan peningkatan kapasitas perawat dengan menambahkan konsep pendekatan spiritual dan teknologi (Suprapto et al., 2021).

Dari berbagai uraian tersebut, terdapat banyak faktor yang mempengaruhi kinerja pegawai di puskesmas. Puskesmas sebagai layanan publik perlu melakukan penilaian dan review kinerja pegawai dalam upaya meningkatkan kapasitas layanan kepada masyarakat. Puskemas Tamalanrea Jaya kota Makassar merupakan sebuah puskemas yang memberikan layanan kesehatan kepada masyarakat yang di wilayah Kecamatan Tamalanrea Kota Makassar. Para pegawai melayani masyarakat yang begitu banyak sehingga banyak masyarakat yang mengeluhkan layanan yang lama dan kualitas yang belum memadai sehingga pada penelitian ini perlu untuk menganalisis faktor yang berpengaruh terhadap kinerja pegawai di Puskesmas Tamalanrea Jaya. Rendahnya kinerja akan membangun citra bentuk puskesmas, dimana pasien yang merasa tidak puas akan menceritakan kepada rekan-rekanya. Begitu juga sebaliknya semakin tinggi kinerja pelayanan yang diberikan akan menjadi nilai plus bagi puskesmas, dalam hal ini pasien akan merasa puas terhadap pelayanan yang diberikan oleh puskesmas. Tujuan; menganalisis faktor yang mempengaruhi kinerja pegawai puskesmas.

\section{Metode}

Rancangan penelitian yang digunakan dalam penelitian ini adalah observasional dengan pendekatan Cross Sectional Study. Yang dilakukan di wilayah kerja Puskesmas Tamalanrea Jaya Kota Makassar. Populasi; seluruh pegawai yang ada di wilayah kerja Puskesmas Tamalanrea Jaya Kota Makassar yakni 35 pegawai yang terdiri dari 25 PNS dan 10 pegawai magang. Pengolahan dan Penyajian Data; Data yang terkumpul diolah dengan menggunakan program SPSS (Statistical Package for the Social Science) for 15. Data disajikan dalam bentuk tabel distribusi dan persentase disertai penjelasan, selain itu dilakukan dalam bentuk tabel analisis. Analisis data; Analisis univariat untuk mendapatkan gambaran umum dengan cara mendiskripsikan tiap-tiap variabel 
yang digunakan dalam penelitian yaitu dengan melihat gambaran distribusi frekuensinya, baik dalam bentuk table maupun bentuk grafik. Analisis bivariat dilakukan untuk melihat hubngan variabel bebas (independent variable) dengan variabel terikat (dependent variable) dengan uji Chi-Square pada tingkat kepercayaan 95\% atau derajat kemanknaan 0,05. untuk melihat hubungan dan besarnya hubungan variabel independen dengan variabel dependen setelah dimasukkan secara bersama-sama. Analisis multivariat yang digunakan dalam penelitian ini adalah regresi logistik. Regresi logistik suatu model matematik yang digunakan untuk mempelajari pengaruh satu atau beberapa variabel independen dengan variabel dependen yang bersifat dikotomi (binary) yang berguna untuk mengukur pengaruh variabel independen terhadap variabel dependen dan meramalkan terjadinya variabel dependen pada individu berdasarkan nilainilai sejumlah variabel prediktor yang ada pada individu tersebut serta dapat mengkonversi koefisien regresi (bi) menjadi Rasio Odds (OR) dengan rumus OR=exp [bi].

\section{Hasil dan Pembahasan}

Tabel 1

Distribusi Frekuensi dan Variabel Penelitian

\begin{tabular}{|c|c|c|}
\hline Karakteristik & $\mathrm{n}=35$ & $\%$ \\
\hline \multicolumn{3}{|l|}{ Kelompok Umur } \\
\hline 20-30 Tahun & 14 & 40,0 \\
\hline 31-37 Tahun & 13 & 37,1 \\
\hline 38-44 Tahun & 5 & 14,3 \\
\hline 45-51Tahun & 3 & 8,6 \\
\hline \multicolumn{3}{|l|}{ Pendidikan } \\
\hline DIII Kebidanan & 7 & 20,0 \\
\hline DIII Keperawatan & 3 & 8,6 \\
\hline DIV/ST & 4 & 11,4 \\
\hline S1 Kesehatan Masyarakat & 12 & 34,3 \\
\hline S1 Kedokteran & 8 & 22,9 \\
\hline Lainnya & 1 & 2,9 \\
\hline \multicolumn{3}{|l|}{ Status Kepegawaian } \\
\hline $\mathrm{ASN}$ & 25 & 71,4 \\
\hline NON ASN & 10 & 28,6 \\
\hline \multicolumn{3}{|l|}{ Bidang Kerja } \\
\hline KIA & 10 & 28,6 \\
\hline KESLING & 8 & 22,9 \\
\hline Surveilans & 8 & 22,9 \\
\hline IGD & 1 & 8,6 \\
\hline LAB & 3 & 2,9 \\
\hline Lainnya & 5 & 14,3 \\
\hline \multicolumn{3}{|l|}{ Masa Kerja } \\
\hline$<10$ Tahun & 20 & 57,1 \\
\hline$\geq 10$ Tahun & 15 & 42,9 \\
\hline \multicolumn{3}{|l|}{ Ikut Pelatian } \\
\hline Ya & 32 & 91,4 \\
\hline Tidak & 3 & 8,6 \\
\hline \multicolumn{3}{|l|}{ Pendidikan } \\
\hline Sesuai & 33 & 94,3 \\
\hline Tidak sesuai & 2 & 5,7 \\
\hline Disiplin Kerja & & \\
\hline
\end{tabular}


Jurnal Ilmiah Kesehatan Sandi Husada

Volume 10 Nomor 2 Desember 2021

\begin{tabular}{cll}
\hline Cukup & 26 & 74,3 \\
Kurang & 9 & 25,7 \\
Motivasi & & \\
Cukup & 12 & 34,3 \\
Kurang & 23 & 65,7 \\
Kompensasi & & \\
Cukup & 10 & 28,6 \\
Kurang & 25 & 71,4 \\
Fasilitas & & \\
Cukup & 24 & 68,6 \\
Kurang & 11 & 31,4 \\
Lingkungan Kerja & & \\
Cukup & 19 & 54,3 \\
Kurang & 16 & 45,7 \\
Kinerja & & 25,7 \\
Cukup & 9 & 74,3 \\
Kurang & 26 &
\end{tabular}

Sumber: Data Primer 2021

Hasil analisis menunjukkan bahwa terdapat 35 pegawai puskesmas tamalarea jaya kota Makassar yang menjadi responden. Responden yang berumur 24-30 tahun sebanyak 14(40,0\%), 31-37 tahun sebanyak 13 (37,1\%), 38-44 tahun sebayak 5(14,3\%) dan reponden yang berumur 45-51 tahun sebanyak 3(8,6\%). Masa kerja yang tela dijalani oleh para responden yaitu yang memiliki masa kerja kurang dari 10 tahun sebanyak 20(57,1\%) sedangkan yang memiliki masa kerja yang lebih dari atau sama dengan 10 tahun sebayak 15 (42,9\%). Pendidikan yang ditempuh para responden dijelaskan bahwa sebayak $7(20,0 \%)$ yang menemuh pendidikan hingga DIII Kebidanan, yang menempuh pendidikan DIII Keperawatan sebanyak $3(8,6 \%)$, untuk DIV/ST sebanyak 4 (11,4\%), S1 kesehatan sebanyak 12 (34,3\%), S1 Kedokteran sebanyak 8 (22,9\%), dan yang menempuh pendidikan di luar daripada itu sebanyak 1 (2,9\%). Status kepegawaian responden ada yang ASN dan NON ASN yang memiliki status ASN sebanyak $25(71,4 \%)$, dan yang NON ASN sebanyak $10(28,6 \%)$. Bidang kerja yang dimiliki responden yaitu yang bekerja sebagai KIA sebanyak 10 (28,6\%), bekerja sebagai KESLING sebanyak $8(22,9 \%)$, pada bidang Surveilans sebanyak $8(22,9 \%)$, di IGD sebanyak $3(8,6 \%)$, pada bidang Laboratorium sebanyak $1(2,9 \%)$, dan yang bekerja diluar dari bidang diatas sebanyak 5 (14,3\%). Kategori pendidikan yang dimiliki para pegawai Puskesmas Tamalanrea Jaya Kota Makassar terbagi atas dua kategori yaitu sesuai dengan bidang kerja dan tidak sesuai dengan bidang kerja, pendidikan pegawai yang termasuk dalam kategori sesuai sebanyak $33(94,3 \%)$,sedangkan yang tidak sesuai hanya 2 $(5,7 \%)$. Sedangkan untuk kategori lainnya terbagi atas dua kategori yaitu cukup dan kurang, pada disiplin kerja responden yang memiliki kedisiplinan kerja yang cukup sebanyak 26 (74,3\%), dan yang kurang sebanyak $9(25,7 \%)$. Untuk motivasi kerja yang dimiliki para responden dengan kategori cukup sebanyak 12 (34,3\%), dan yang kurang memiliki motivasi sebanyak 23 (65,7\%). Untuk kompensasi yang didapatkan pegawai kerja Puskesmas Tamalanrea Jaya dengan kategori yang cukup sebanyak $10(28,6 \%)$, namun yang merasa kurang dalam mendapatkan kompensasi sebanyak $25(71,4 \%)$.

Fasilitas yang didapatkan pegawai kerja dengan kategori cukup sebanyak $24(68,6 \%)$, dan yang mendapatkan fasilitas kerja yang kurang sebanyak 11 (31,4\%). Lingkungan kerja yang dimiliki pegawai puskesmas dengan kategori cukup sebanyak 19 (54,3\%), dan yang memiliki lingkungan kerja kurang sebanyak $16(45,7 \%)$. Untuk kinerja pegawai Puskesmas Tamalanrea Jaya dengan kategori cukup sebanyak 9 (25,7\%), dan yang kategori kurang sebanyak $26(74,3 \%)$. 
Tabel 2

Pengaruh Antara Variabel Terhadap Kinerja Pegawai Puskesmas

\begin{tabular}{|c|c|c|c|c|c|c|c|}
\hline \multirow[t]{3}{*}{ Variabel } & \multirow{2}{*}{\multicolumn{2}{|c|}{$\begin{array}{l}\text { Kinerja } \\
\text { Cukup }\end{array}$}} & \multirow{2}{*}{\multicolumn{2}{|c|}{ Kurang }} & \multirow{2}{*}{\multicolumn{2}{|c|}{ Total }} & \multirow[t]{3}{*}{$\rho$ value } \\
\hline & & & & & & & \\
\hline & $\mathbf{n}$ & $\%$ & $\mathbf{n}$ & $\%$ & $n=35$ & $\%$ & \\
\hline \multicolumn{8}{|l|}{ Pendidikan } \\
\hline Sesuai & 9 & 27,3 & 24 & 72,7 & 33 & 100 & \multirow[b]{2}{*}{0,546} \\
\hline Tidak sesuai & 0 & 0 & 2 & 100 & 2 & 100 & \\
\hline \multicolumn{8}{|l|}{ Disiplin Kerja } \\
\hline Cukup & 8 & 30,8 & 18 & 69,2 & 26 & 100 & \multirow[t]{2}{*}{0,243} \\
\hline Kurang & 1 & 11,1 & 8 & 22,9 & 9 & 100 & \\
\hline \multicolumn{8}{|l|}{ Motivasi } \\
\hline Cukup & 8 & 66,7 & 4 & 33,3 & 12 & 100 & \multirow[t]{2}{*}{0,000} \\
\hline Kurang & 1 & 4,3 & 22 & 95,7 & 23 & 100 & \\
\hline \multicolumn{8}{|l|}{ Kompensasi } \\
\hline Cukup & 8 & 80,0 & 2 & 20,0 & 10 & 100 & \multirow[t]{2}{*}{0,000} \\
\hline Kurang & 9 & 25,7 & 26 & 74,3 & 35 & 100 & \\
\hline \multicolumn{8}{|l|}{ Fasilitas } \\
\hline Cukup & 7 & 29,2 & 17 & 70,8 & 24 & 100 & \multirow{2}{*}{0,403} \\
\hline Kurang & 2 & 18,2 & 9 & 81,8 & 11 & 100 & \\
\hline \multicolumn{8}{|c|}{ Lingkungan Kerja } \\
\hline Cukup & 2 & 10,5 & 17 & 89,5 & 19 & 100 & \multirow[t]{2}{*}{0,031} \\
\hline Kurang & 7 & 43,8 & 9 & 56,3 & 16 & 100 & \\
\hline
\end{tabular}

Sumber: Data primer 2021

Menunjukkan bahwa dari 35 pegawai kerja Puskesmas Tamalanrea Jaya di Kota Makassar, 33 pegawai kerja yang memiliki pendidikan yang sesuai terdapat 9 (27,3\%) yang memiliki kinerja yang cukup dan terdapat $24(72,7 \%)$ dengan kinerja yang kurang. Sedangkan dari 2 pegawai kerja yang memiliki pendidikan yang tidak sesuai dengan kinerja yang kurang. Uji statistik chi-square menghasilkan nilai $\rho$ value $=0,546>\rho$ standar $/ 0,05$ yang membuktikan bahwa tidak ada pengaruh kesesuaian pendidikan dan bidang kerja dengan kinerja pegawai kerja Puskesmas Tamalanrea Jaya di Kota Makassar. Hasil penelitian juga menunjukkan bahwa dari 26 pegawai kerja yang memiliki disiplin kerja yang cukup sebanyak 8 (30,8\%) dengan kinerja yang cukup dan $18(69,2 \%)$ dengan kinerja yang kurang. Sedangkan dari 9 pegawai kerja yang memiliki disiplin kerja yang kurang hanya $(4,3 \%)$ yang memiliki kinerja yang cukup, dan 8 $(22,9 \%)$ yang memiliki kinerja yang cukup. Uji statistik chi-square menghasilkan nilai $\rho$ value= $0,243>\rho$ standar $/ 0,05$ yang membuktikan bahwa tidak ada pengaruh disiplin kerja dengan kinerja pegawai kerja Puskesmas Tamalanrea Jaya di Kota Makassar. Pada penelitian ini ditemukan motivasi kerja pegawai Puskesmas Tamalanrea Jaya di Kota Makassar, dari 12 pegawai yang memiliki motivasi cukup terdapat $8(66,7 \%)$ kinerja yang cukup, dan $4(33,3 \%)$ yang memiliki kinerja yang kurang. Sedangkan untuk pegawai kerja yang memiliki motivasi yang kurang terdapat 23 dan diantaranya ada sekitar $1(4,3 \%)$ dengan kinerja yang cukup dan $22(74,3 \%)$ dengan pegawai kerja yang kurang. Uji statistik chi-square menghasilkan nilai $\rho$ value $=0,000<$ $\rho$ standar/0,05 yang membuktikan bahwa ada pengaruh motivasi yang dimiliki pegawai kerja dengan kinerja pegawai kerja Puskesmas Tamalanrea Jaya di Kota Makassar.

Kompensasi yang didapatkan para pegawai kerja Puskesmas Tamalanrea Jaya yang cukup terdapat 12 diantaranya teradapat $8(80,0 \%)$ dengan kinerja yang cukup, dan terdapat sekitar $2(20,0 \%)$ yang memiliki kerja yang kurang. Sedangkan sebanyak 2 orang pegawai yang mendapatkan kompensasi yang kurang dan terdapat $9(25,7 \%)$ dengan kinerja yang cukup, namun $26(74,3 \%)$ yang memiliki kinerja yang kurang. Uji statistik chi-square menghasilkan nilai $\rho$ value $=0,000<\rho$ standar $/ 0,05$ yang membuktikan bahwa ada pengaruh antara kompensasi yang didapatkan dengan kinerja pegawai kerja Puskesmas Tamalanrea Jaya di Kota Makassar. 
Fasilitas yang didapatkan pegawai selama bekerja dengan kategori cukup sebanyak 24 di antaranya terapat $7(29,2 \%)$ dengan tingkat kinerja yang cukup namun terdapat $17(70,8 \%)$ yang memiliki tingkat kerja yang kurang. Sedangkan pegawai yang mendapatkan fasilitas yang kurang sebanyak 11 dengan $2(18,2 \%)$ yang memiliki kinerja yang cukup dan $9(81,8 \%)$ yang memiliki kinerja yang kurang . Uji statistik chi-square menghasilkan nilai $\rho$ value $=0,403>\rho$ standar $/ 0,05$ yang membuktikan bahwa tidak ada pengaruh fasilitas yang didapatkan dengan kinerja pegawai kerja Puskesmas Tamalanrea Jaya di Kota Makassar. Lingkungan kerja pegawai yang cukup terdapat 19 dengan $2(10,5 \%)$ yang memiliki kinerja yang cukup dan terdapat 17 (89,5\%) dengan kinerja yang kurang. Sedangkan untuk lingkungan kerja yang termasuk dalam kategori kurang terdapat sekitar 16 diantaranya terdapat $7(43,8 \%)$ yang memiliki kinerja yang cukup dan 9 $(56,3 \%)$ degan kinerja yang kurang. Uji statistik chi-square menghasilkan nilai $\rho$ value $=0,031<$ $\rho$ standar/0,05 yang membuktikan bahwa ada pengaruh lingkungan kerja pegawai dengan kinerja pegawai kerja Puskesmas Tamalanrea Jaya di Kota Makassar.

\section{Tabel 3}

Hasil Seleksi Kandidat Model Berdasarkan Variabel yang Memiliki Pengaruh Terhadap Kinerja Pegawai

\begin{tabular}{lll}
\hline No. & Variabel Sosiokultural & p value \\
1 & Motivasi & 0,000 \\
2 & Kompensasi & 0,000 \\
3 & Lingkungan Kerja & 0,031 \\
\hline \multicolumn{2}{c}{ Sumber: Data primer $2021^{*}$ dikeluarkan dari model jika $\rho$ value $>0,05$}
\end{tabular}

Berdasarkan hasil analisis bivariat, diperoleh variabel pendidikan, disiplin kerja dan fasilitas yang memiliki nilai memiliki nilai $\rho$ value $>$ (lebih besar dari) $\rho$ standar 0,05 sehingga dieleminasi dalam tahapan analisis selanjutnya.

Tabel 4

Hasil Analisis Multyple Logistic Regression Variabel yang Berpengaruh Terhadap Kinerja Pegawai Puskesmas Tamalanrea Jaya Kota Makassar

\begin{tabular}{lllllll}
\hline Variabel & \multirow{2}{*}{ Exp $(\mathbf{B})$} & \multirow{2}{*}{ Std. Err. } & t & Sig. & \multicolumn{2}{c}{ [95\% Conf. Interval } \\
lower & upper \\
Motivasi & 17,109 & 28420,720 &, 000 & 1,000 & 0,374 & 84,298 \\
Kompensasi & $-21,567$ & 28420,720 &, 000 & 0,999 & 0,000 & - \\
$\begin{array}{l}\text { Lingkungan } \\
\text { Kerja }\end{array}$ & 1,762 & 1,382 & 1,559 & 0,212 & 0,000 & - \\
Constant & 2,369 & 1,090 & 4,724 & 0,030 & & \\
\hline
\end{tabular}

Sumber: Data primer 202

Menunjukkan bahwa dari 3 variabel yang telah dianalisis dengan uji Multyple Logistic Regression ditemukan dengan interpretasi bahwa nilai exp (B) dari motivasi sebesar 17,109 yang menunjukkan bahwa semakin tinggi motivasi, maka kinerja akan meningkat sebesar 17,109. Lingkungan kerja juga demikian, semakin baik lingkungan kerja maka akan meningkatkan kinerja sebesar 1,762 kali

\section{Pembahasan}

Hasil penelitian juga menunjukkan bahwa dari 26 pegawai kerja yang memiliki disiplin kerja yang ukup sebanyak 8 (30,8\%) dengan kinerja yang cukup dan 18 (69,2\%) dengan kinerja yang kurang. Sedangkan dari 9 pegawai kerja yang memiliki disiplin kerja yang kurang hanya $(4,3 \%)$ yang memiliki kinerja yang cukup, dan $8(22,9 \%)$ yang memiliki kinerja yang cukup. Uji statistik chi-square menghasilkan nilai $\rho$ value $=0,243>\rho$ standar $/ 0,05$ yang membuktikan bahwa 
tidak ada pengaruh disiplin kerja dengan kinerja pegawai kerja Puskesmas Tamalanrea Jaya di Kota Makassar.

Hodges mengatakan disiplin dapat diartikan sebagai sikap seseorang atau kelompok yang berniat untuk mengikuti aturan-aturan yang telah ditetapkan. Dalam kaitannya dengan pekerjaan, pengertian disiplin kerja adalah suatu sikap dan tingkah laku yang menunjukkan ketaatan karyawan terhadap peraturan organisasi (Hidayati, 2017). Kenyataan yang tidak bisa dipungkiri, sebelum masuk sebuah organisasi, seorang karyawan tentu mempunyai aturan, nilai dan norma sendiri, yang merupakan proses sosialisasi dari keluarga atau masyarakatnya. Seringkali terjadi aturan, nilai dan norma diri tidak sesuai dengan aturan-aturan organisasi yang ada. Hal ini menimbulkan konflik sehingga orang mudah tegang, marah atau tersinggung apabila orang terlalu menjunjung tingggi salah satu aturannya (Fadila, 1996). Penelitian tentang pengaruh motivasi dan disiplin kerja terhadap kinerja karyawan di Puskesmas Talise menunjukkan bahwa motivasi dan disiplin kerja secara bersama-sama berpengaruh signifikan terhadap variabel kinerja pegawai pada Puskesmas Talise. Dari hasil pehitungan uji t hitung X1 = 2,203 pada taraf kesalahan 5\% atau nilai probabilitas $0,05>0,039$, hal ini menunjukkan bahwa motivasi (X1) secara parsial mempunyai pengaruh yang signifikan terhadap variable Kinerja pegawai (Y) pada Puskesmas Talise. Dari hasil pehitungan uji t hitung X2 $=4,166$ pada taraf kesalahan $5 \%$ atau nilai probabilitas 0,05>0,000 ini menunjukkan bahwa variabel disiplin kerja (X2) secara parsial mempunyai pengaruh yang signifikan terhadap variabel kinerja pegawai (Y) pada Puskesmas Talise (Rukhyati, 2018). Menurut (Ahmad, 2020) bahwa ada hubungan antara sindrom premenstruasi dengan kinerja pada perawat ICU.

Pada penelitian ini ditemukan motivasi kerja pegawai Puskesmas Tamalanrea Jaya di Kota Makassar, dari 12 pegawai yang memiliki motivasi cukup terdapat $8(66,7 \%)$ kinerja yang cukup, dan $4(33,3 \%)$ yang memiliki kinerja yang kurang. Sedangkan untuk pegawai kerja yang memiliki motivasi yang kurang terdapat 23 dan diantaranya ada sekitar $1(4,3 \%)$ dengan kinerja yang cukup dan $22(74,3 \%)$ dengan pegawai kerja yang kurang. Uji statistik chi-square menghasilkan nilai $\rho$ value $=0,000<\rho$ standar $/ 0,05$ yang membuktikan bahwa ada pengaruh motivasi yang dimiliki pegawai kerja dengan kinerja pegawai kerja Puskesmas Tamalanrea Jaya di Kota Makassar.

Motivasi adalah daya penggerak atau kekuatan yang menyebabkan suatu tindakan atau perbuatan. Seseorang melakukan suatu tindakan pada umumnya mempunyai suatu motif dengan melakukan sesuatu tentu mempunyai maksud atau tujuan yang mendorongnya untuk melakukan suatu tindakan. Motivasi merupakan kondisi atau energi yang menggerakkan diri karyawan yang terarah dan bertujuan untuk mencapai tujuan organisasi perusahaan (Mangkunegara, 2011). Sebuah penelitian tentang pengaruh budaya organisasi, motivasi kerja dan pengalaman kerja terhadap kinerja pegawai Puskesmas, menunjukkan bahwa motivasi kerja berpengaruh positif dan signifikan terhadap kinerja pegawai. Artinya motivasi kerja mampu membuat perubahan terhadap kinerja pegawai (Utomo, 2011). Kepuasan kerja menggambarkan bagaimana konten seseorang dengan pekerjaannya. Ini adalah istilah yang relatif baru karena pada abad-abad sebelumnya pekerjaan yang tersedia untuk orang tertentu sering kali ditentukan sebelumnya oleh pekerjaan orang tua orang tersebut (Parvin \& Kabir, 2011).

Kompensasi yang didapatkan para pegawai kerja Puskesmas Tamalanrea Jaya yang cukup terdapat 12 diantaranya teradapat $8(80,0 \%)$ dengan kinerja yang cukup, dan terdapat sekitar $2(20,0 \%)$ yang memiliki kerja yang kurang. Sedangkan sebanyak 2 orang pegawai yang mendapatkan kompensasi yang kurang dan terdapat $9(25,7 \%)$ dengan kinerja yang cukup, namun $26(74,3 \%)$ yang memiliki kinerja yang kurang. Uji statistik chi-square menghasilkan nilai $\rho$ value $=0,000<\rho$ standar $/ 0,05$ yang membuktikan bahwa ada pengaruh antara kompensasi yang didapatkan dengan kinerja pegawai kerja Puskesmas Tamalanrea Jaya di Kota Makassar.

Kinerja pegawai adalah hasil kerja secara kualitas dan kuantitas yang dicapai oleh seseorang pegawai dalam melaksanakan tugasnya sesuai dengan tanggungjawab yang diberikan 
Jurnal Ilmiah Kesehatan Sandi Husada

Volume 10 Nomor 2 Desember 2021

kepadanya. Peningkatan kinerja merupakan hal terpenting yang diinginkan baik oleh pegawai maupun organisasi. Organisasi menginginkan kinerja yang optimal untuk kepentingan peningkatan hasil kerja dan keuntungan organisasi. Disisi lain, pegawai berkepentingan untuk pengembangan diri dan promosi pekerjaan. The Influence of Work Discipline and Compensation to the Employee Performance: A Case Study of PT Temasindo Intipratama, South Jakarta menunjukkan bahwa disiplin kerja berpengaruh positif dan tidak signifikan dan kompensasi juga berdampak tidak signifikan terhadap kinerja karyawan. Disiplin kerja dan kompensasi berdampak kecil terhadap kinerja secara bersamaan. Kontribusi kinerja pegawai hanya dipengaruhi oleh faktof disiplin kerja dan kompensasi sebesar 20\% (Pratama \& Pinasthika, 2021). Menurut (Suprapto et al., 2020) bahwa aling dominan dengan keterlaksanaan perkesmas adalah adanya interaksi antara kompetensi dan pelatihan.

Fasilitas yang didapatkan pegawai selama bekerja dengan kategori cukup sebanyak 24 di antaranya terapat $7(29,2 \%)$ dengan tingkat kinerja yang cukup namun terdapat $17(70,8 \%)$ yang memiliki tingkat kerja yang kurang. Sedangkan pegawai yang mendapatkan fasilitas yang kurang sebanyak 11 dengan $2(18,2 \%)$ yang memiliki kinerja yang cukup dan $9(81,8 \%)$ yang memiliki kinerja yang kurang. Uji statistik chi-square menghasilkan nilai $\rho$ value $=0,403<\rho$ standar $/ 0,05$ yang membuktikan bahwa tidak ada pengaruh fasilitas yang didapatkan dengan kinerja pegawai kerja Puskesmas Tamalanrea Jaya di Kota Makassar.

Fasilitas kerja yang memadai akan meningkatkan seorang pegawai akan memiliki prestasi kerja. Dimana fasilitas kerja yang lengkap akan mendukung orang yang bekerja didalamnya akan membuat pegawai akan menjadi lebih berkreasi (Noviana, 2021). Sebuah penelitian tentang pengaruh kemampuan, fasilitas kerja dan kompetensi terhadap kinerja pegawai Puskesmas Rantau Kecamatan Rantau Kabupaten Aceh Tamiang menunjukkan bahwa terdapat pengaruh yang signifikan kemampuan kerja terhadap kinerja pegawai, terdapat pengaruh fasilitas kerja terhadap kinerja pegawai, komitmen kerja memiliki pengaruh terhadap kinerja. Kemampuan kerja, fasilitas dan komitemn secara bersama-sama berpengaruh signifikan terhadap kinerja pegawai Puskemas Rantau Kabupaten Aceh Tamiang sebesar 61,9\% sedangkan sisanya sebesar $41 \%$ dijelaskan oleh variabel lain yang tidak dimasukkan ke dalam model penelitian ini ((Hakim, 2020). Penelitian lain tentang pengaruh job insecurity, fasilitas kerja dan karakteristik individu terhadap prestasi kinerja pegawai Puskesmas Bromo Medan menunjukkan bahwa terdapat pengaruh yang signifikan job insecurity terhadap kinerja pegawai. Terdapat pengaruh fasilitas kerja terhadap kinerja, fasilitas kerja akan memiliki hasil yang tinggi jika pegawai memiliki fasilitas kerja yang baik. Karakteristik individu berpengaruh terhadap kinerja pegawai. Job insecurity, fasilitas kerja dan karakteristik individu secara bersama-sama berpengaruh signifikan terhadap kinerja pegawai di Puskesmas Bromo (Nasution, 2020).

Lingkungan kerja pegawai yang cukup terdapat 19 dengan $2(10,5 \%)$ yang memiliki kinerja yang cukup dan terdapat $17(89,5 \%)$ dengan kinerja yang kurang. Sedangkan untuk lingkungan kerja yang termasuk dalam kategori kurang terdapat sekitar 16 diantaranya terdapat 7 $(43,8 \%)$ yang memiliki kinerja yang cukup dan $9(56,3 \%)$ degan kinerja yang kurang. Uji statistik chi-square menghasilkan nilai $\rho$ value $=0,031<\rho$ standar $/ 0,05$ yang membuktikan bahwa ada pengaruh lingkungan kerja pegawai dengan kinerja pegawai kerja Puskesmas Tamalanrea Jaya di Kota Makassar.

Lingkungan kerja pegawai adalah suatu kondisi berupa suhu yang terlalu panas, terlalu dingin, terlalu sesak, kurang cahaya, dan semacamnya. Ruangan yang terlalu panas menyebabkan ketidaknyamanan seseorang dalam menjalankan pekerjaanya, begitu juga ruangan yang terlalu dingin. Panas tidak hanya dalam pengertoan udara. Disamping itu, kebisingan juga memberi andil tidak kecil munculnya stres kerja, sebab beberapa orang sangat sensitif pada kebisingan dibanding dengan yang lain. Sebuah penelitian tentang pengaruh gaya kepemimpinan dan lingkungan kerja fisik terhadap kinerja pegawai Puskesmas Pasar Baru Rantau Panjang Kecamatan Tabir menunjukkan bahwa variabel gaya kepemimpinan secara parsial berpengaruh positif dan signifikan terhadap kinerja dan variabel lingkungan kerja fisik secara parsial berpengaruh positif 
dan signifikan terhadap kinerja pegawai. Variabel gaya kepemimpinan dan lingkungan kerja fisik secara simultan berpengaruh positif dan signifikan terhadap kinerja pegawai pada Puskesmas pasar Baru Rantau Panjang Kecamatan Tabir (Wariyadi, 2021). Penelitian tentang pengaruh kompetensi, lingkungan kerja dan motivasi terhadap kinerja pegawai pada Puskesmas Kecamatan Tanah Siang menunjukkan bahwa kompetensi berpengaruh signifikan terhadap kinerja, kompetensi mampu mempengaruhi kinerja pegawai. Hal ini berarti semakin tinggi kompetensi maka kinerja pegawai semakin meningkat. Lingkungan kerja berpengaruh signifikan terhadap kinerja. Variasi dari lingkungan kerja dapat mempengaruhi kinerja pegawai. Motivasi memiliki pengaruh yang signifikan terhadap kinerja. Motivasi mampu mempengaruhi kinerja (Apridani et al., 2021). Perencanaan, pengorganisasian, pengarahan, pengawasan kepala ruangan terhadap kinerja perawat pelaksana dalam memberikan asuhan keperawatan. Kapasitas manajerial kepala ruangan dalam mengelola pelayanan keperawatan dan merumuskan kebijakan sistem seleksi dalam pengangkatan kepala ruang berbasis kompetensi (Mulat \& Hartaty, 2019). Fokus dan upaya khusus diperlukan secara khusus pada faktor-faktor lingkungan kerja dan hubungan tim dan rekan kerja karena mereka telah menunjukkan dampak yang lebih tinggi secara signifikan pada keterlibatan karyawan dan karenanya kinerja karyawan. Organisasi harus fokus pada menghadirkan lingkungan yang hebat bagi karyawan untuk bekerja dan mempromosikan program yang akan meningkatkan hubungan rekan kerja (Anitha, 2014).

\section{Simpulan Dan Saran}

Bahwa motivasi, lingkungan kerja dan kompensasi memiliki pengaruh terhadap kinerja pegawai. Sedangkan pendidikan, disiplin kerja dan fasilitias tidak memiliki pengaruh terhadap kinerja pegawai. Peningkatan kompensasi atau upah maupun penghargaan kepada para pegawai akan meningkatkan kinerja para pegawai. Pemberian pendidikan dan pelatihan kepada para pegawai agar mampu melaksanakan tugas yang diemban secara profesional.

\section{Ucapan Terimakasih}

Kepada para tim peneliti atas kontribusi dalam penyelesaian penelitian ini. Kepada pihak progam pascasarjana STIK Tamalatea Makassar

\section{Daftar Rujukan}

Ahmad, E. (2020). Sindrom Premenstruasi terhadap Kinerja Perawat Intensive Care Unit di Rumah Sakit Kota Makassar. Jurnal Ilmiah Kesehatan Sandi Husada, 9(1 SE-Articles). https://doi.org/10.35816/jiskh.v11i1.232

Anitha, J. (2014). Determinants of employee engagement and their impact on employee performance. International journal of productivity and performance management.

Apridani, A., Mantikei, B., \& Syamsudin, A. (2021). Pengaruh kompetensi, lingkungan kerja dan motivasi terhadap kinerja pegawai pada Puskesmas Kecamatan Tanah Siang. Journal of Environment and Management, 2(1), 82-88.

Bukhori, I. (2015). Hubungan Antara Motivasi Berprestasi dan Locus of Control Terhadap Learning Outcome. Jurnal Kompilasi Ilmu Ekonomi (KOMPILEK), 6(1), 1-11.

Hakim, A. (2020). Pengaruh Kemampuan, Fasilitas Kerja dan Kompetensi Terhadap Kinerja Pegawai Puskesmas Rantau Kecamatan Rantau Kabupaten Aceh Tamiang. Tijarah: Jurnal Ekonomi dan Bisnis, 2(20).

Hidayati, A. (2017). Hubungan Health Locus Of Control Dengan Mekanisme Koping Pada Pasien Diabetes Melitus Tipe 2 Di Wilayah Kerja Puskesmas Patrang Kabupaten jember.

Ismandani, F., Chamariyah, C., \& Subijanto, S. (2021). Pengaruh Budaya Organisasi, Motivasi Kerja Dan Pengalaman Kerja Terhadap Kinerja Pegawai Puskesmas Giligenting Kabupaten Sumenep. Ekonomika45, 8(1), 28-36.

Mangkunegara, A. A. A. P. (2011). Manajemen sumber daya manusia perusahaan.

Mulat, T., \& Hartaty, H. (2019). Pengaruh Peran Kepala Ruangan Terhadap Kinerja Perawat Dalam Pemberian Asuhan Keperawatan Diruang Rawat Inap. Jurnal Ilmiah Kesehatan 
Sandi Husada, 8(2 SE-Articles). https://doi.org/10.35816/jiskh.v10i2.105

Nasution, N. (2020). Pengaruh Job Insecurity, Fasilitas Kerja Dan Karakteristik Individu Terhadap Prestasi Kinerja Pegawai Puskesmas Bromo Medan. Tijarah: Jurnal Ekonomi dan Bisnis, 2(20).

Noviana, R. (2021). Pengaruh Kemampuan Kerja Dan Fasilitas Kerja Terhadap Prestasi Kerja Tenaga Kesehatan Di Puskesmas Tebing Bulang Kecamatan Sungai Keruh Kabupaten Musi Banyuasin. 021008 Universitas Tridinanti Palembang.

Parvin, M. M., \& Kabir, M. M. N. (2011). Factors affecting employee job satisfaction of pharmaceutical sector. Australian journal of business and management research, 1(9), 113.

Pratama, A., \& Pinasthika, L. A. G. (2021). The Influence of Work Discipline and Compensation to the Employee Performance: A Case Study of PT Temasindo Intipratama, South Jakarta.

Rukhyati, R. (2018). Pengaruh Motivasi Dan Disiplin Kerja Terhadap Kinerja Karyawan Di Puskesmas Talise. Jurnal Sinar Manajemen, 5(2), 98-104.

Suprapto, S., Herman, H., \& Asmi, A. (2020). Nurse Competency and Managing Level of Community Health Care Activities. Jurnal Ilmiah Kesehatan Sandi Husada, 12(2 SEArticles). https://doi.org/10.35816/jiskh.v12i2.386

Suprapto, S., Rifdan, R., \& Gani, H. A. (2021). Nurse capacity-building strategy in health services in hospitals. Linguistics and Culture Review, 5(S1 SE-), 832-838. https://doi.org/10.37028/lingcure.v5nS1.1467

Suprapto Suprapto. T.C., Lalla, N.S.N., M. (2021). Nurse competence in implementing public health care. International Journal of Public Health Science, 10(2), 428-432.

Susanto, E. (2018). Pengaruh Efikasi Diri, Disiplin Kerja Dan Pelayanan Terhadap Kinerja Pegawai Puskesmas Di Kecamatan Lempuing Jaya Kabupaten Ogan Komering Ilir. Derivatif: Jurnal Manajemen, 12(2).

Utomo, J. (2011). Pengaruh motivasi kerja, kepuasan kerja, dan komitmen organisasional terhadap kinerja pegawai (studi pada pegawai setda Kabupaten Pati). Jurnal Analisis Manajemen, 5(1), 75-86.

Wariyadi, S. (2021). Pengaruh Gaya Kepemimpinan Dan Lingkungan Kerja Fisik Terhadap Kinerja Pegawai Puskesmas Pasar Baru Rantau Panjang Kecamatan Tabir. Jurnal Manajemen Sains, 1(1).

Widianti, R. F., Noor, H. M., Kala, R., \& Linggi, M. S. (2018). Kinerja Pegawai Puskesmas Dalam Pelayanan Kesehatan Di Kecamatan Sangatta Selatan Kabupaten Kutai Timur. EJournal Ilmu Pemerintahan, 6(1), 185-198. 